WellBeing International

WBI Studies Repository

$5-2012$

\title{
Blood Cortisol Concentrations Predict Boldness in Juvenile Mulloway (Argyosomus japonicus)
}

\author{
Vincent Raoult \\ Macquarie University \\ Culum Brown \\ Macquarie University \\ Amina Zuberi \\ Macquarie University \\ Jane E. Williamson \\ Macquarie University
}

Follow this and additional works at: https://www.wellbeingintlstudiesrepository.org/acwp_asie

Part of the Animal Studies Commons, Comparative Psychology Commons, and the Other Animal Sciences Commons

\section{Recommended Citation}

Raoult, V., Brown, C., Zuberi, A., \& Williamson, J. E. (2012). Blood cortisol concentrations predict boldness in juvenile mulloway (Argyosomus japonicus). Journal of ethology, 30(2), 225-232.

This material is brought to you for free and open access by WellBeing International. It has been accepted for inclusion by an authorized administrator of the WBI Studies Repository. For more information, please contact wbisr-info@wellbeingintl.org.

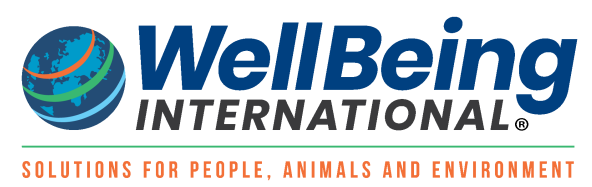




\title{
Blood cortisol concentrations predict boldness in juvenile mulloway (Argyosomus japonicus)
}

Vincent Raoult, Culum Brown, Amina Zuberi, and Jane E. Williamson

Macquarie University

\section{KEYWORDS}

personality, stress, Cortisol, mulloway, marine fish, boldness

\begin{abstract}
There is a growing interest in animal personality because individual variation is the substrate of the evolutionary process. Despite revelations that personality traits affect key fitness variables, little is known about the proximate mechanisms generating consistent behavioural differences between individuals. Boldness, the propensity to take risks, is one of the most widely studied aspects of personality in fishes. We assessed the position of juvenile Argyosomus japonicus on the "boldness-shyness" continuum by repeatedly recording the time taken to exit a refuge and explore a novel environment. Stress-related hormone concentrations after exposure to a mild stressor were analysed 1 month before behavioural assays and found to be significantly linked to boldness scores. Shy fish had significantly higher plasma cortisol concentrations in response to handling stress than bold fish. Spontaneous switching between personality categories occurred between trials, highlighting the importance of repeated testing of personality traits over time to correctly attribute personality.
\end{abstract}

\section{Introduction}

Consistent individual differences in behaviour have often been brushed aside as noise around an optimum population-behavioural response. The recent resurgence of papers investigating animal personality traits, however, has revealed that much of this variation may be adaptive and is reminiscent of alternative life-history strategies. Consistent differences in behaviour have been variously labelled as coping styles (Budaev 1997), temperament (Shaklee 1963), behavioural strategies (Murphy and Pitcher 1991), syndromes (Sih et al. 2004), and personality (Mather and Anderson 1993). Both genes and experience shape animal personality traits during ontogeny (Brown et al. 2007b; Mousseau and Fox 1998), and the expression of personality traits has multiple fitness consequences (Dingemanse et al. 2004; Brown et al. 2007a). Personality traits, therefore, are a crucial aspect of the evolutionary process (Colleter and Brown 2011).

Studies examining the responses of a range of animals to aversive stimuli collectively indicate that two strategies can often be identified in both wild and captive populations: proactive and reactive coping styles (Koolhaas et al. 1999). Reactive individuals tend to be less aggressive, and flexible in the response to stimuli whereas the opposite is true of proactive types. Thus the manner in which individuals respond behaviourally to various stressors may have fitness consequences that are context-specific (Brown et al. 
2007a). These contrasting coping strategies most likely reflect alternative adaptive responses that are suited to differences in environmental stability. Proactive individuals perform well under highly stable environmental conditions, whereas reactive individuals may perform better in less stable conditions where flexibility is required to adapt to new situations. Thus the continuum of personality traits often observed in wild and captive reared populations is likely to reflect the extent of environmental variability given that no given personality type would be optimum across all potential environmental conditions. If we accept that environmental variables shape personality traits, then we might expect that domestication and captive rearing may strongly affect the distribution of behavioural types in a population via artificial selection and phenotypic plasticity (Huntingford and Adams 2005).

Despite the large number of studies investigating personality in a range of experimental circumstances, few have attempted to determine the proximate mechanisms generating personality types. The boldnessshyness continuum is the most widely studied dimension of personality (reviewed by Budaev and Brown 2011). Boldness refers to the propensity to take risks and is considered closely linked to how individuals react to stressful situations (Pankhurst and Sharples 1992). Studies on the links between stress reactivity and behavioural responses have been studied in fish (Øverli et al. 2007), and studies in other taxa have revealed links between boldness traits and stress responses (Carere and van Oers 2006). Blood cortisol concentration is one of the most commonly used stress indicators in fish (Clearwater and Pankhurst 1997; Begg and Pankhurst 2004). Recently, receptor activation has been linked to coping strategies in carp Cyprinus carpio (Huntingford et al. 2010)—cortisol receptor gene activation was significantly lower for bold fish than for shy fish. In addition, corticosterone concentration in greylag geese Anser anser is positively correlated with "aggressiveness" (Kralj-Fišer et al. 2009). Hierarchy positions have also been linked to cortisol concentrations and a range of personality traits in fish (Øverli et al. 2004; Colleter and Brown 2011). Similar correlations between personality and cortisol responses have been recorded in humans (Oswald et al. 2006) and primates (Capitanio et al. 2004), suggesting that cortisol levels are closely linked to personality expression in vertebrates generally.

Despite the importance of marine species in global fisheries and aquaculture industries, few studies have assessed boldness in marine fishes (Millot et al. 2009). Studies of this kind are particularly relevant to the aquaculture industry on a number of levels. First, in intensive systems, high levels of stress and a tendency to over-react to novel stimuli can reduce growth rates and, hence, overall productivity (Pickering 1993). Identification of stress-prone fish may help aquaculturists to select for low-stress lines. Although testing plasma cortisol concentrations in response to a stressor is plausible for selecting low-stress stocks (reviewed by Øverli et al. 2005), it is also expensive. Consequently it is important to identify low-cost alternatives, for example behavioural measures, to identify stress-prone individuals. Second, many fish populations around the world rely on hatchery-derived stock to bolster wild numbers either to maintain a viable commercial or recreational fishing industry or for conservation reintroduction programs (Brown and Laland 2001). Rearing fish in highly artificial systems causes significant shifts in the behavior of the fish towards optima for life in a hatchery but away from traits suitable for life in the wild. For example, hatchery selection has been found to increase boldness in brown trout (Sundstrom et al. 2003). Such selection may lead to enhanced risk-taking post-release, with associated high mortality (Brown and Day 2002). Moreover, studies in this area have been limited because of the costly facilities required to study of large marine species, despite the clear benefits to industry.

In the work reported here we determined whether a commercial marine fish species, mulloway, Argyosomus japonicus, could be assigned a position on the bold-shy continuum, and if individuals' blood cortisol concentrations after exposure to a stressor could be linked to their boldness score. This species was successfully tested for an aquaculture industry in New South Wales, Australia (Battaglene and Talbot 1994; Fielder and Bardsley 1999), making it an ideal candidate for a study of this kind. 


\section{Materials and methods}

\section{Study animals}

A. japonicus were hatched in Port Stephens, NSW, and reared in sea pens located in Botany Bay, NSW $\left(34^{\circ} 00^{\prime} \mathrm{S} ; 151^{\circ} 14^{\prime} \mathrm{E}\right)$. The fish used in this study were from the same spawning event with multiple parents from a bloodline originating from fish caught in Botany Bay. The 131 individuals used in the study were 300-400 mm total length, approximately 2 years old, on the basis of age/growth estimates (Fielder and Bardsley 1999), and sexually immature (Silberschneider et al. 2009). While in the sea pens, fish were weaned on to $5 \mathrm{~mm}$ pellet feed and fed $\sim 1-2 \%$ of their estimated total weight per day. The rearing of these fish was based on accepted commercial hatchery techniques and consequently the fish were ideal candidates for study of aquaculture-related questions. The individuals were transported to Cronulla Fisheries Research Centre of Excellence in a $1000 \mathrm{~L}$ tank aerated with pure oxygen, and AQUI-S at 5 $\mathrm{mL} / 1000 \mathrm{~L}$ for anaesthesia.

Before experimentation, fish were housed in two $5000 \mathrm{~L}$ tanks under an outdoor covered area exposed to natural variations in diurnal light and wind. Mean stocking densities were between 5 and $10 \mathrm{~kg} / \mathrm{m}^{3}$, close to the optimum determined by Pirozzi et al. (2008). Experimental and holding tanks were $5000 \mathrm{~L}(2.4 \mathrm{~m}$ diameter $\times 1.2 \mathrm{~m}$ depth), made of fibreglass and had fresh seawater flowing through at a constant rate of $5 \mathrm{~L} / \mathrm{min}$ from the adjacent bay in Cronulla. The tanks were continuously aerated with stone diffusers, and water temperature was ambient to the bay, thus resulting in temperatures that varied seasonally (14 \pm $2^{\circ} \mathrm{C}$, mean $\pm 1 \mathrm{SE}$, during the study). Fish were fed on the same diet as at the hatchery (5 mm pellet feed). The experimental tank was protected by a tarpaulin to limit wind and direct sunlight exposure and to reduce the effect of other environmental conditions.

\section{Cortisol assay}

To obtain a measure of the cortisol response after a moderately stressful event and to facilitate identification of individuals, blood samples were taken during a PIT tag implantation procedure 1 month before the "boldness" experiments. Handling fish in this way is common in the industry and thus investigating the response to handling stress is a useful and highly applicable approach. Trovan ID100 PIT tags (Microchips Australia, Victoria, Australia) measuring $2.2 \times 11 \mathrm{~mm}$ were inserted into the body cavity posterior to the pectoral fins, via a specialized needle inserter, and the point of insertion was sealed by use of cyanoacrylate in accordance with Raoult et al. (2011). The tags ( $0.09 \mathrm{~g})$ weighed less than $0.001 \%$ of fishes' total weight, agreeing with Winter's (1996) minimum weight ratio for implanted tags of less than $2 \%$ total fish weight, which reduces adverse implantation effects. Fish were anaesthetized in two stages by an immersion in a solution of AQUI-S (clove oil extract). AQUI-S is widely used as an anaesthetic in aquaculture, and can significantly reduce blood cortisol levels in response to stressful events (Inoue et al. 2005). This product was used because of its non-toxicity compared to other anaesthetics (MS222 for example). The primary anaesthesia was applied to the stocking tank at 0.5 $\mathrm{ml} / 100 \mathrm{~L}$ to reduce stress in fish and allow them to be easily caught. This procedure negated any selection for bold or shy individuals during the process, because the fish did not attempt to avoid being netted. The second immersion was to enable painless surgery and was at $1 \mathrm{~mL} / 100 \mathrm{~L}$ just before the surgery. The fish was placed in a metal pan and held with a wet towel, the pit tag was inserted and a 1 $\mathrm{mL}$ blood sample was obtained from the caudal vein below the lateral line and behind the anal fin by use of a 21-Ga sterile needle attached to $2 \mathrm{~mL}$ syringe. Fish were assumed to consider the procedure stressful, thus the blood sample should contain cortisol at concentrations indicative of that individual's stress response. Each procedure was of similar duration (ca. $5 \mathrm{~min}$ ) for each individual, thus acting as a standardised stressor. The entire process occurred during 1 day, from 8:00 am to 4:00 pm. Circadian rhythms are known to effect blood cortisol levels, particularly in association with feeding (Boujard and 
Leatherland 1992), but, because mulloway are nocturnal feeders, this is unlikely to have affected the results in this instance.

The blood samples were immediately placed in heparinized tubes and kept on ice for no more than $6 \mathrm{~h}$ then transported back to the laboratory facilities at Macquarie University, Sydney. There, plasma was immediately separated from the sample by centrifugation at $3000 \mathrm{rpm}$ (or $2000 \mathrm{~g}$ relative centrifugal force) for $15 \mathrm{~min}$ at $4^{\circ} \mathrm{C}$ then stored at $20^{\circ} \mathrm{C}$ until further analysis. After the procedure, fish were placed in a recuperation tank where fresh seawater was gently forced through their gills to aid in recovery and to flush any remaining anaesthetic out of their system. When they had recovered, as indicated by correct buoyancy and active swimming, fish were returned to a holding tank containing fresh seawater. No mortality was recorded during the procedure or throughout the following 8 months of experimentation. When the project concluded, fish were moved to a larger $(-20000 \mathrm{~L})$ pen where they remained under the same conditions.

A cortisol radioimmunoassay was conducted on the blood samples with a coat-a-count kit from Diagnostic Products Corporation (Los Angeles, CA, USA). Although this kit has not yet been officially validated for use on fish cortisol, it has been used with success in previous studies (Earley et al. 2006). Before the assay, samples were left to warm to room temperature and mixed by gentle swirling and inversion. To increase the accuracy of results each sample was run in duplicate and the average was calculated. plasma $(25 \mu \mathrm{L})$ from each sample was then pipetted into antibody-coated polypropylene tubes followed by addition of $1 \mathrm{~mL}{ }^{125}$ l-labelled cortisol. Tubes were then vortex mixed and incubated in a $37^{\circ} \mathrm{C}$ bath for $45 \mathrm{~min}$. The liquid in each sample was then decanted, blotted, and left to dry for 30 min before quantification. A gamma counter then recorded the emissions for 1 min.

\section{Boldness assessment}

Boldness tests were conducted at least 1 month after blood sampling occurred to ensure that the two measures were temporally independent, because stress resulting from the blood-sampling procedure could have affected the results. The personality experiment determined the degree of boldness or shyness of each individual fish by use of a novel environment test, which was based on the classic open field test used for rodents (Walsh and Cummins 1976) but also used in many fish-based studies (Brown and Braithwaite 2004; Yoshida et al. 2005; Cote et al. 2010). The time taken for the fish to leave a refuge and begin exploring a novel environment was used as a measure of boldness. The species is known to use rocky shores and crevices found in its natural environment as a means of anti-predator defence (Taylor et al. 2006), thus emergence from refuge is an ideal test of boldness. Strong lights were added over the tank (not present over their usual holding pen, which remained dark) to further highlight the safety of the refuge from the risky environment outside. Although other techniques used to assess boldness were attempted, to obtain a broader measure of this personality trait in other contexts (e.g. responses to novel objects), we found that only the novel environment assay was feasible for this species.

Each individual was taken from the holding tank housing all the fish, identified with a PIT reader (Trovan LID650 reader and ANT C270 antenna) and placed into the experimental tank's refuge box $(60 \times 50 \times 40$ $\mathrm{cm}$ ). Fish were captured at random and there was no evidence of an order effect in the data (see "Results"). Only one fish was tested at a time. The refuge box was constructed of opaque plastic fitted with a swinging outer door. The box was placed against the wall on the bottom of the tank, with the door facing outwards, and each fish was given 2 min to acclimatise itself with its surroundings. Immediately after this acclimatisation period, the trap door was opened remotely via a rope mechanism and the tank was left undisturbed until the fish left the confines of the box. If the fish had not left the box after 5 min, the trial was terminated. Five minutes was chosen as a "ceiling period" after preliminary testing lasting 
over 30 min during which highly bimodal behaviour patterns were evident. It was apparent that fish that did not emerge in $5 \mathrm{~min}$ were very reluctant to emerge even after $30 \mathrm{~min}$. The fish's behavior was monitored remotely via a video camera (Sony HDD AVCHD) mounted $1 \mathrm{~m}$ above the tank to remove any observer effect. To avoid further disturbance to fish that had not been tested, tested fish were placed in a different holding pen at the end of the experiment. Water inflow was set to maximum ( $100 \mathrm{~L} / \mathrm{min})$ to flush any chemical cues from the previous individual out of the experimental tank between trials, and stopped during trials to avoid disturbing fish behaviour. Up to 25 individuals passed through the experiment each day, with a day between tests to reduce potential stress levels until all the tagged fish had been through the experimental procedure once $(n=131)$. The boldness assay was then repeated 1 month later.

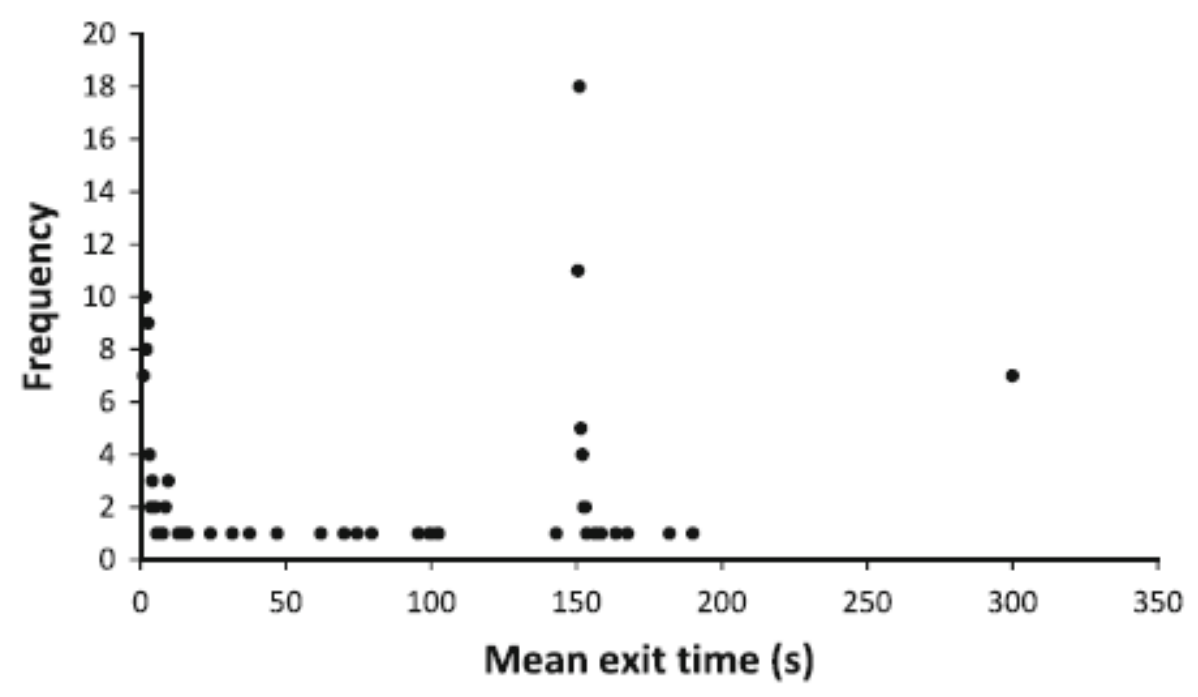

Fig. 1 Distribution of fish population relative to mean exit time over the two personality assays

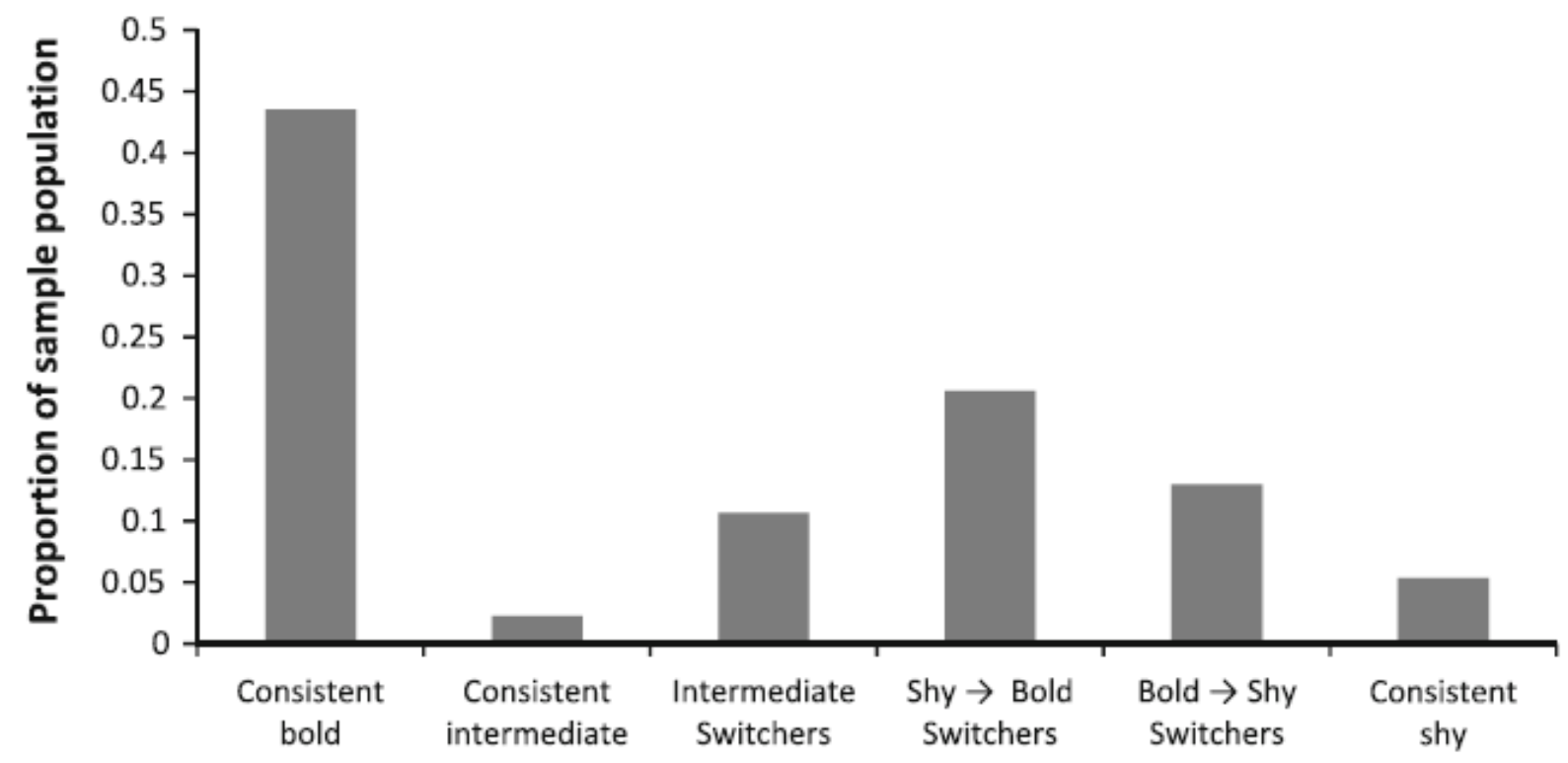

Fig. 2 Swapping occurrence from first to second "boldness" assay relative to "boldness" categories 
Video analysis was used to assign a "boldness factor" to each individual. Fish were considered to have left the box only when their entire body had left the enclosure. Based on the "boldness" frequency distribution scores obtained, an individual whose mean exit time across the two tests was under $10 \mathrm{~s}$ after the trap door was opened were considered "bold" (near-immediate exit from the box). Individuals that took between 10 and $149 \mathrm{~s}$ to leave the box were considered "intermediates", and individuals that remained in the box for > $150 \mathrm{~s}$ were considered "shy". This categorization was used rather than continuous sampling, because of the extreme bimodality of the distribution and to provide better comparisons with previous "boldness" experiments. Fish were assigned to groups on the basis of consistency between the two boldness assays. This identified those that were consistently bold, shy, or intermediate in both trials and those that switched boldness category between trials.

Cortisol concentrations were tested by regression analysis and found to be significantly positively linked to the order the fish were sampled $\left(r^{2}=0.06, d f=77, F=5.44, P=0.022\right)$, so an ANCOVA was used to analyse the results, with sample order as a covariate and cortisol concentrations as a dependant variable. Cortisol concentrations were log transformed to comply with the assumptions of parametric tests.

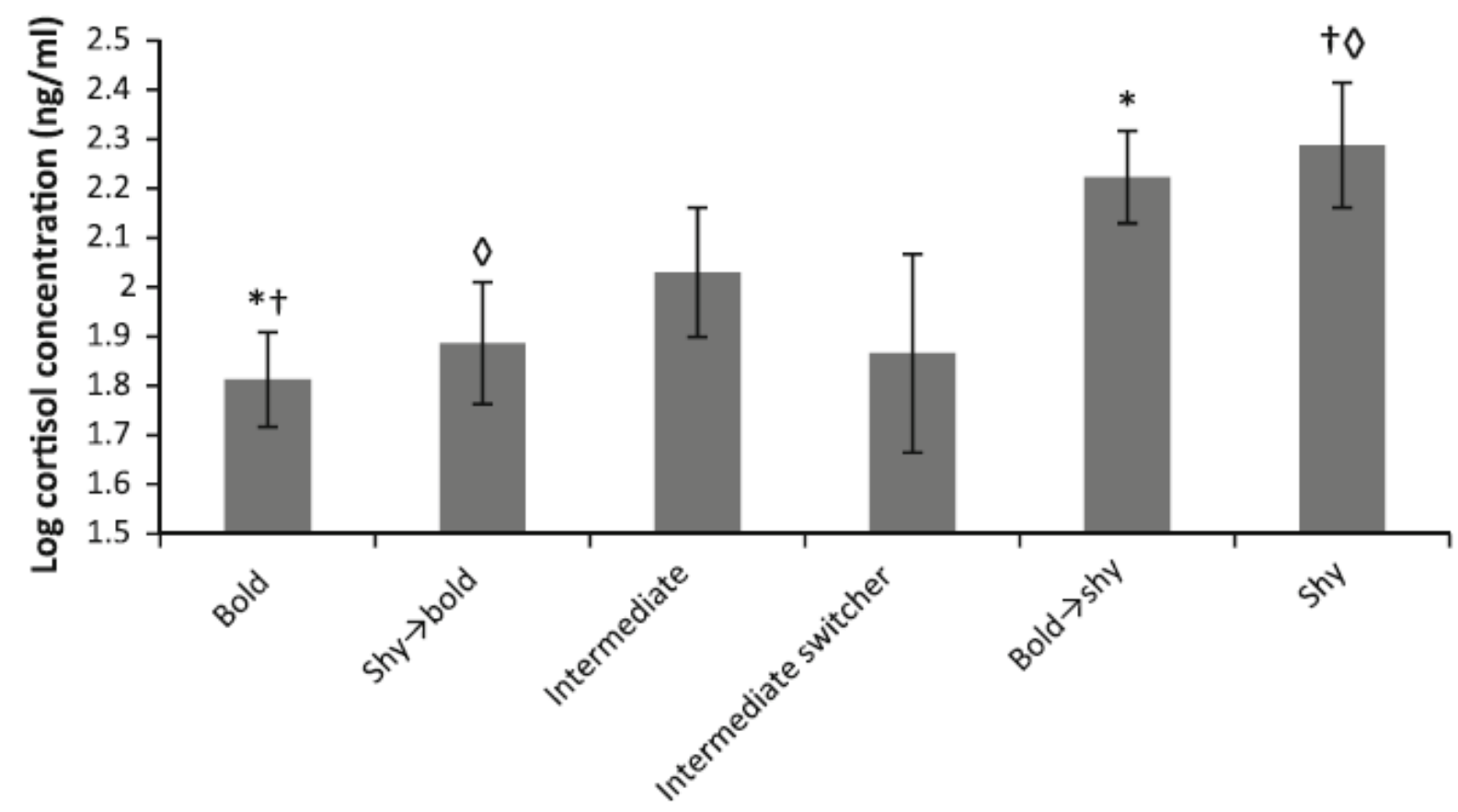

Fig. 3 ANCOVA mean ( $\pm 1 \mathrm{SE}$ ) log cortisol concentrations in different fish personality categories with testing order as a covariate. Asterisks, daggers, and open diamonds indicate group pairs with significantly different means

\section{Results}

Exit times had a strong bimodal distribution (Fig. 1). Not all the fish that completed the boldness tests could be analysed because of problems extracting the cortisol from the blood sample (blood sample slightly too small, blood partially coagulated). "Switching" from one classification to another between trials was observed for $40 \%$ of individuals (Fig. 2). Nineteen (14\%) initially bold individuals displayed shy behaviour during the second replicate, and 27 (20\%) initially shy individuals displayed bold behavior 
during the second replicate. Some fish displayed intermediate behaviour and also switched during the other test. A rank correlation test did not find significant repeatability between trials $(r=-0.043, P=0.62)$. ANOVA of mean refuge exit time between the experimental days yielded a significant difference $(d f=12$, $\mathrm{F}=0.77, P=0.02$ ), but this was generated by data from a single day in the middle of the test period that by chance had a larger proportion of shy individuals than all other test days. Moreover, there was no significant correlation between the order that the fish were tested and the time taken to leave the refuge $\left(r^{2}=0.003, F=0.77, P=0.38, d f=260\right.$; regression used did not assume normal distribution). The first personality assay was less correlated with cortisol concentration than the second assay $\left(r^{2}<0.01, F=\right.$ $0.02, P=0.89, d f=78 ; r^{2}=0.11, F=9.1, P<0.01, d f=78$ for the first and second assay, respectively). After correction for cortisol sampling time, there were significant links between cortisol concentrations and individual personality types (ANCOVA: $d f=5, F=1.71, P<0.05$, Fig. 3). Significant differences in cortisol concentrations were found between bold and shy individuals, between shy $\rightarrow$ bold switchers and shy individuals, and between bold $\rightarrow$ shy switchers and bold individuals ( $t$ tests: $P<0.05$ in all cases).

\section{Discussion}

Boldness was clearly linked to underlying hormone released in response to handling stress in juvenile Argyosomus japonicus. Fish with varying scores of boldness differed significantly in the level of cortisol in the bloodstream measured 1 month before the onset of the behavioural assays. Shy fish had significantly higher blood cortisol concentrations than bold fish, as hypothesized. When considered together with the conclusions of Huntingford et al. (2010), these results suggest that shy fish have higher circulating levels of cortisol in their bloodstream when exposed to a stressor in comparison with bold fish. Thus it is likely that shy fish are more responsive to potentially stressful situations (Huntingford et al. 2010).

In this study, juvenile $A$. japonicus responses to an open field test were not consistent over the course of 1 month. Interestingly, the results herein revealed that the second exposure to the boldness assay was more indicative of an individual's boldness score given the far tighter correlation with blood cortisol concentrations at the time. Fish that switched from bold to shy had cortisol concentrations that were more similar to those of the consistently shy fish, whereas concentrations for those that switched from shy to bold were more similar to those of consistently bold fish. Thus, the first exposure to a novel environment assay was not as indicative of personality as previously presumed. Indeed, factor analysis of behavioural responses in rodents has shown that first exposure could be affected by conflict resolution between fear and exploration (Markel et al. 1989). Repeated exposure to the same assay reduces the novelty component, but it is likely that fish still found the brightly lit experimental arena threatening on their second exposure (Shuranova et al. 2005).

Switching occurred toward both sides of the boldness spectrum, rather than just towards boldness as would be expected during habituation. Such switching could not have been because fish were reaching sexual maturity, because the study fish were far smaller than the average size at maturity (males mature at $50 \mathrm{~cm}$ TL and females at $68 \mathrm{~cm}$; Silberschneider et al. 2009). Seasonal hormonal changes were also unlikely to have affected results because the experiments were conducted in the middle of winter, when seasonal variations are minimum $\left( \pm 2^{\circ} \mathrm{C}\right)$. Irrespective of the extent of switching observed, the significant link between blood cortisol concentrations and personality suggests our measurements were accurate and that these behavioural fluctuations are a natural part of the boldness spectrum. Future studies could expose fish to the same assay several times, with monitoring of the rate of habituation. In this scenario, one would predict that bold fish would rapidly habituate to the arena, but shy fish would continue to treat the procedure as potentially threatening.

Although we expected some behavioural plasticity, the number of individuals defying this pattern was totally unexpected. This pattern was all the more surprising because previous studies have suggested 
consistency in the neophobic responses of animals over time (Frost et al. 2007; Wilson and Godin 2009). A cursory glance at the data suggests that these results are in accordance with coping style theory (bold fish generally remain bold, other personality types are more malleable), however, there were approximately even proportions of bold and shy switchers (Fig. 2). The results are deceptive, because of the larger number of bold individuals than shy ones. We believe our replicate measurements enable more accurate placement of animal personality along the boldness continuum. This continuum varies from consistently bold to consistently shy, with a variety of plasticity between these two personality extremes.

Despite using hatchery-reared study animals, which were expected to have undergone some selection for boldness (Sundstrom et al. 2003), we still observed substantial individual variation in our population. In general we observed a slight increase in cortisol concentration as the sampling progressed, which reflected the length of time the fish were kept in the lightly anaesthetised state while blood samples were taken. The low $r^{2}$ value suggests that the effect of time was rather small, nevertheless we included sample number as a covariate in the analysis.

In aquaculture environments there are several potential stressors, including social interactions and human disturbances that are more frequent than in the natural environment, and responses to these stressors are associated with cortisol stress responses (Øverli et al. 2000, 2004; Zuberi et al. 2011). In addition, hatchery-reared fish tend to have a higher energy intake, because of high provisioning, and thus elevated metabolism compared with their wild counterparts, which also pushes hatchery fish toward risktaking behaviour (swimming close to the surface where they are vulnerable to birds) as they attempt to gain access to food items (Lepage et al. 2000; Sundstrom et al. 2004; Killen et al. 2011). As stress responses are partially heritable, selection for low stress lines can result in enhanced hatchery efficiency ( $\varnothing v e r l i$ et al. 2006). Thus, hatcheries must carefully manage the behavioural profile of their stocks to suit the objective of the program. While reducing stress and enhancing boldness may be beneficial for fish destined for the table, managers rearing fish for restocking programs must address the multifaceted behavioural effects of hatchery rearing conditions to maximise post-release survival.

We believe there is a direct causal link between how animals respond to stress and their propensity to take risks (boldness; Pankhurst and Sharples 1992). Risk taking is largely about stress management. Exposure to environmental stressors, for example predators, causes elevated stress levels (Brown et al. 2005) and measuring responses to predators is often used as a proxy for boldness (Budaev and Brown 2011). We suggest that individuals that show low reactivity to potentially stressful situations will be generally bolder across a range of contexts (similar to the proactive coping strategy Koolhaas et al. 1999), although there is conflicting evidence in this area (Coleman and Wilson 1998; Sinn et al. 2008). Consequently, context-elated personality should be another topic of research on A. japonicus. While this study concentrated solely on stress hormones, it is likely that other key hormones (e.g. testosterone and other androgens) affect personality traits in A. japonicus and in a vast array of animals. For example, quail chicks that had $50 \mathrm{ng}$ of testosterone injected into their yolk were more likely than sham-injected chicks to approach novel objects, with the treatment affecting both sexes equally (Niall Daisley et al. 2005). Testosterone is already known to affect masculinisation in cichlids (Harbott et al. 2007), and male tropical poeciliids were found to be bolder than females (Brown et al. 2007a). Indeed, a high level of risktaking behaviour is a ubiquitous male character across a wide range of vertebrate species. Boldness, activity, and aggression have also been linked to male hierarchy positioning, suggesting that these traits have substantial fitness consequences (Colleter and Brown 2011). These studies indicate probable causal links between androgens expression and personality that warrant further investigation. A recent study focussing on the masculinisation (both physical and behavioural) of female mosquitofish using high doses of cortisol confirms this idea (Knapp et al. 2011). Moreover, we predict that personality traits in juvenile Argyosomus japonicus will vary temporally because of fluctuations in hormone concentrations 
over time, for example during the breeding season, when an increase in boldness would increase relative fitness. These conclusions agree with previous literature on coping strategies and the growing evidence of links between physiological traits and behavioural responses found not only in fish (Clement et al. 2005; Huntingford et al. 2010) but also across a range of other vertebrates (Clarke et al. 1988; Kralj-Fišer et al. 2009), which is indicative of the widespread effects of hormones on behaviour.

Study of animal personality traits is becoming widespread yet there is still no consensus regarding the appropriate methodology (Dingemanse et al. 2009; reviewed by Budaev and Brown 2011). A great many studies focusing on personality do not repeat their personality assays (Bell 2005; Brown and Braithwaite 2004; Godin and Dugatkin 1996) despite there being evidence that personality shows a high degree of induced plasticity (Frost et al. 2007; Ruiz-Gomez et al. 2008). Our observations suggest that repeated testing of personality traits using the same assay or a range of different assays provides a far more accurate indication of an animal's personality than a single trial.

\section{Acknowledgments}

This study would not have been possible without the aid of the NSW Department of Industry and Investment's Cronulla Fisheries Research Centre of Excellence and Dave Barker. All experiments were conducted in accordance with Macquarie University's Animal Ethics and Care approval number 2009/008. Thanks to Mariella Herberstein for providing invaluable publication advice and to those who helped with the experiments or checking this publication.

\section{References}

Battaglene SC, Talbot RB (1994) Hormone induction and larval rearing of mulloway, Argyosomus hololepidotus (Pisces: Sciaenidae). Aquaculture 126:73-81

Begg K, Pankhurst NW (2004) Endocrine and metabolic responses to stress in a laboratory population of the tropical damselfish Acanthochromis polyacanthus. J Fish Biol 64:133-145

Bell A (2005) Behavioural differences between individuals and two populations of stickleback (Gasterosteus aculeatus). J Evol Biol 18:464-473

Boujard T, Leatherland JF (1992) Circadian rhythms and feeding time in fishes. Environ Biol Fish 35:109131

Brown C, Braithwaite VA (2004) Size matters: a test of boldness in eight populations of the poeciliid Brachyraphis episcopi. Anim Behav 68:1325-1329

Brown C, Day RL (2002) The future of stock enhancements: lessons for hatchery practice from conservation biology. Fish Fish 3:79-94

Brown C, Gardner C, Braithwaite V (2005) Differential stress responses in fish from areas of high and low predation pressure. J Comp Physiol B 175:305-312

Brown C, Laland K (2001) Social learning and life skills training for hatchery-reared fish. J Fish Biol 59:471-493

Brown C, Burgess F, Braithwaite VA (2007a) Heritable and experiential effects on boldness in a tropical poeciliid. Behav Ecol Sociobiol 62:237-243

Brown C, Jones FC, Braithwaite VA (2007b) Correlation between boldness and body mass in natural populations of Brachyraphis episcopi. J Fish Biol 71:1509-1601

Budaev SV (1997) Alternative styles in the European wrasse, Symphodus ocellatus: boldness related schooling tendency. Environ Biol Fish 49:71-78 
Budaev SV, Brown C (2011) Personality and behaviour. In: Brown C, Laland K, Krause J (eds) Fish cognition and behaviour, 2nd edn. Wiley-Blackwell, UK

Capitanio JP, Mendoza SP, Bentson KL (2004) Personality characteristics and basal cortisol concentrations in adult male rhesus macaques (Macaca mulatta). Psychoneuroendocrynology 29:1300-1308

Carere C, van Oers K (2006) Shy and bold great tits (Parus major): body temperature and breath rate in response to handling stress. Phys Behav 82:905-912

Clarke AS, Mason WA, Moberg GP (1988) Differentiall behavioral and adrenocortical responses to stress among three macaque species. Am J Primatol 14:37-52

Clearwater SJ, Pankhurst NW (1997) The response to capture and confinement stress of plasma cortisol, plasma sex steroids and vitellogenic oocytes in the marine teleost, red gurnard. J Fish Biol 50:429-441

Clement TS, Parikh V, Schrumpf M, Fernald RD (2005) Behavioral coping strategies in a cichlid fish: the role of social status and acute stress response in direct and displaced aggression. Horm Behav 47:336-342

Coleman K, Wilson DS (1998) Shyness and boldness in pumpkinseed fish: individual differences are context-specific. Anim Behav 56:927-936

Colleter M, Brown C (2011) Personality traits predict hierarchy rank in male rainbowfish (Melanotaenia duboulayi) social groups. Anim Behav 81:1231-1237

Cote J, Fogarty S, Weinersmith K, Brodin T, Sih A (2010) Personality traits and dispersal tendency in the invasive mosquitofish (Gambusia affinis). Proc R Soc B Sci 277:1571-1579

Dingemanse NJ, Both C, Drent PJ, Tinbergen JM (2004) Fitness consequences of avian personalities in a fluctuating environment. Proc Biol Sci 271:847-852

Dingemanse NJ, Kazem AJN, Réale D, Wright J (2009) Behavioural reaction norms: animal personality meets individual plasticity. Trends Ecol Evol 25:81-89

Earley RL, Edwards JT, Aseem O, Felton K, Blumer LS, Karom M, Grober MS (2006) Social interactions tune aggression and stress responsiveness in a territorial cichlid fish (Archocentrus nigrofasciatus). Psych Behav 88:353-363

Fielder DS, Bardsley W (1999) A preliminary study on the effects of salinity on growth and survival of mulloway Argyrosomus japonicus larvae and juveniles. J World Aquac Soc 30:380-387

Frost AJ, Winrow-Giffen A, Ashley PJ, Sneddon LU (2007) Plasticity in animal personality traits: does prior experience alter the degree of boldness? Proc R Soc B Sci 274:333-339

Godin JG, Dugatkin LA (1996) Female mating preference for bold males in the guppy, Poecilia reticulata. Proc Natl Acad Sci USA 93:10262-10267

Harbott LK, Burmeister SS, White RB, Vagell M, Fernald RD (2007) Androgen receptors in a cichlid fish, Astatotilapia burtoni: structure, localization, and expression levels. J Comp Neurol 504:57-73

Huntingford F, Adams C (2005) Behavioural syndromes in farmed fish: implications for production and welfare. Behaviour 142:1207-1221

Huntingford FA, Andrew G, Mackenzie S, Morera D, Coyle SM, Pilarczyk M, Kadri S (2010) Coping strategies in a strongly schooling fish, the common carp Cyprinus carpio. J Fish Biol 76:15761591

Inoue LAKA, Afonso LOB, Iwama GK, Moraes G (2005) Effects of clove oil on the stress response of matrinxa (Brycon cephalus) subjected to transport. Acta Amaz 35:289-295

Killen SS, Marras S, McKenzie DJ (2011) Fuel, fasting, fear: routine metabolic rate and food deprivation exert synergistic effects on risk-taking in individual juvenile European sea bass. J Anim Ecol 80:1024-1033

Knapp R, Marsh-Matthews E, Vo L, Rosencrans S (2011) Stress hormone masculinizes female morphology and behaviour. Biol Letters 7:150-152 
Koolhaas JM, Korte SM, De Boer SF, Van Der Vegt BJ, Van Reenen CG, Hopster H, De Jong IC, Ruis MAW, Blokhuis HJ (1999) Coping styles in animals: current status in behavior and stressphysiology. Neurosci Behav Rev 23:925-935

Kralj-Fišer S, Weiß B, Kotrschal K (2009) Behavioural and physiological correlates of personality in greylag geese (Anser anser). J Ethol 28:363-370

Lepage O, Øverli $\varnothing$, Petersson E, Jarvi T, Winberg S (2000) Differential stress coping in wild and domesticated sea trout. Brain Behav Evol 56:259-268

Markel AL, Galaktionov YK, Efimov VM (1989) Factor analysis of rat behavior in an open field test. Neurosci Behav Physiol 19:279-286

Mather JA, Anderson RC (1993) Personalities of octopuses (Octopus rubescens). J Comp Psych 107:336-340

Millot S, Bégout ML, Chatain B (2009) Risk-taking behavior variation over time in sea bass Dicentrarchus labrax: effects of day-night alternation, fish phenotypic characteristics and selection for growth. J Fish Biol 75:1733-1749

Mousseau TA, Fox CW (1998) The adaptive significance of maternal effects. Trends Ecol Evol 13:403407

Murphy KE, Pitcher TJ (1991) Individual behavioural strategies associated with predator inspection in minnow shoals. Ethology 88:307-319

Niall Daisley J, Bromundt V, Möstl E, Kotrschal K (2005) Enhanced yolk testosterone influences behavioral phenotype independent of sex in Japanese quail chicks Coturnix japonica. Horm Behav 47:185-194

Oswald LM, Zandi P, Nestadt G, Potash JB, Kalaydjian AE, Wand GS (2006) Relationship between cortisol response to stress and personality. Neuropsychopharmacology 31:1583-1591

$\varnothing$ verli $\varnothing$, Harris CA, Winberg S (2000) Short-term effects of fights for social dominance and the establishment of dominant-subordinate relationships on brain monoamines and cortisol in rainbow trout. Brain Behav Evol 54:263-275

$\varnothing$ verli $\varnothing$, Korzan WJ, Larson ET, Winberg S, Lepage O, Pottinger TG, Renner KJ, Summers CH (2004) Behavioural and neuroendocrine correlates of displaced aggression in trout. Horm Behav 45:324-329

$\varnothing$ verli $\varnothing$, Winberg S, Pottinger TG (2005) Behavioural and neuroendocrine correlates of selection for stress responsiveness in rainbow trout-a review. Integr Comp Biol 45:463-474

$\varnothing$ verli $\varnothing$, Sørensen C, Kiessling A, Pottinger TG, Gjoen HM (2006) Selection for improved stress tolerance in rainbow trout (Oncorhynchus mykiss) leads to reduced feed waste. Aquaculture 261:776-781

Øverli $\varnothing$, Sørensen C, Pulman KGT, Pottinger TG, Korzan W, Summers CH, Nilsson GE (2007) Evolutionary background for stress coping styles: relationships between physiological, behavioural, and cognitive traits in non-mammalian vertebrates. Neurosci Biobehav Rev 31:396412

Pankhurst NW, Sharples DF (1992) Effects of capture and confinement on plasma cortisol concentrations in the snapper (Pagrus auratus). Mar Freshw Res 43:345-355

Pickering AD (1993) Growth and stress in fish production. Aquaculture 111:51-63

Pirozzi I, Booth MA, Pankhurst PM (2008) The effect of stocking density and repeated handling on the growth of juvenile mulloway. Aquacult Int 17:199-205

Raoult V, Brown C, Williamson JE (2011) Superglue is not super: an assessment of superglue for suturing tag incisions in a cultured marine fish. J World Aquac Soc (in press)

MdL Ruiz-Gomez, Kittilsen S, Ho"glund E, Huntingford FA, Sørensen C, Pottinger TG, Bakken M, Winberg S, Korzan WJ, Øverli $\varnothing$ (2008) Behavioral plasticity in rainbow trout (Oncorhynchus mykiss) with divergent coping styles: when doves become hawks. Horm Behav 54:534-538 
Shaklee AB (1963) Comparative studies of temperament: fear responses in different species of fish. J Gen Psychol 102:295

Shuranova Z, Burmistrov Y, Abramson Cl (2005) Habituation to a novel environment in the crayfish Procambrus cubensis. J Crust Biol 25:488-494

Sih A, Bell A, Johnson JC (2004) Behavioral syndromes: an ecological and evolutionary overview. Trends Ecol Evol 19:372-378

Silberschneider V, Gray CA, Stewart J (2009) Age, growth, maturity and the overfishing of the iconic sciaenid, Argyosomus japonicus, in south-eastern, Australia. Fish Res 95:220-229

Sinn DL, Gosling SD, Moltschaniwskyj NA (2008) Development of shy/bold behaviour in squid: contextspecific phenotypes associated with developmental plasticity. Anim Behav 75:433-442

Sundstrom LF, Petersson E, Hojesjo J, Johnsson JL, Jarvi T (2003) Hatchery selection promotes boldness in newly hatched brown trout (Salmo trutta): implications for dominance. Behav Ecol 15:192-198

Sundstrom LF, Lohmus M, Johnsson JI, Devlin RH (2004) Growth hormone transgenic salmon pay for growth potential with increased predation mortality. Proc R Soc Lon B 271:S350-S352

Taylor MW, Laffan SD, Fielder DS, Suthers IM (2006) Key habitat and home range of mulloway Argyrosomus japonicus in a southeast Australian estuary: finding the estuarine niche to optimize stocking. Mar Ecol Prog Ser 328:237-247

Walsh RN, Cummins RA (1976) The open-field test: a critical review. Psychol Bull 83:482-504

Wilson ADM, Godin J-GJ (2009) Boldness and behavioural syndromes in the bluegill sunfish, Lepomis macrochirus. Behav Ecol 20:231-237

Winter JD (1996) Advances in underwater biotelemetry. In Murphy BRD, Willis DW (eds) Fisheries techniques, 2nd edn. American Fisheries Society, Bethesda, pp 555-590

Yoshida M, Nagamine M, Uematsu K (2005) Comparison of behavioural responses to a novel environment between three teleosts, bluegill Lepomis machrochirus, crucian carp Cassius langsdorfii, and goldfish Carassius auratus. Fish Sci 71:314-319

Zuberi A, Ali S, Brown C (2011) A non-invasive assay for monitoring stress responses: a comparison between wild and captive-reared rainbowfish (Melanoteania duboulayi). Aquaculture (in press) 